\title{
Being-in-the-flow: expert coping as beyond both thought and automaticity
}

\author{
Joshua A. Bergamin ${ }^{1}$
}

Published online: 5 May 2016

(C) The Author(s) 2016. This article is published with open access at Springerlink.com

\begin{abstract}
Hubert Dreyfus argues that explicit thought disrupts smooth coping at both the level of everyday tasks and of highly-refined skills. However, Barbara Montero criticises Dreyfus for extending what she calls the 'principle of automaticity' from our everyday actions to those of trained experts. In this paper, I defend Dreyfus' account while refining his phenomenology. I examine the phenomenology of what I call 'esoteric' (as opposed to 'everyday') expertise to argue that the explicit thought Montero invokes belongs rather to 'gaps' between or above moments of reflexive coping. However, I agree that the 'principle of automaticity' does not adequately capture the experience of performing such skills. Drawing on examples of expert performance in sport and improvised music and dance, I argue that esoteric action, at its best, is marked by a distinct state of non-conceptual awareness- an experience of spontaneity, flow and 'owned-ness'- that distinguishes it from the automaticity of everyday actions.
\end{abstract}

Keywords Dreyfus · Expertise · Coping · Improvisation · Flow · Montero · Heidegger Authenticity

Dreyfus $(2005,2007,2013)$ has long argued that philosophers can profit from attending to the phenomenology of expertise. He claims that the actions of expert athletes and artists performing 'in the flow,' like our everyday dealings with hammers and cars, reveal a non-conceptual mode of cognition. However, Barbara Montero (2010, 2013) criticises Dreyfus for extending what she calls the 'Principle of Automaticity' from our everyday actions to those of trained experts. True experts, she claims, do not act on autopilot- their impressive skills require a constant monitoring and desire to improve that can only be achieved by the explicit thinking that Dreyfus believes is an

Joshua A. Bergamin

joshua.bergamin@uqconnect.edu.au

1 Durham University, 50-1 Old Elvet, Durham DH1 3HN, UK 
impediment to 'smooth coping.' Thus, she argues, the centrality of non-conceptual smooth coping in expertise is over-emphasised by Dreyfus.

In this paper I defend Dreyfus' account while refining his phenomenology to take into account Montero's claim that highly-trained experts are not acting purely automatically. I therefore argue for a third possibility, a kind of being-in-the-flow that is experienced nonconceptually, yet is truly spontaneous rather than automatic. I begin by expanding upon Collins and Evans' (2007) important distinction between the 'everyday' expertise with which we get about in the world, including such tasks as cycling to work or chopping firewood, and the 'esoteric' expertise of highly-trained artists, athletes, and craftsfolk. I then examine the phenomenology of 'esoteric' expertise to argue that, while Montero is wrong to emphasise the role of explicit thinking in expert action, she is right to fault Dreyfus on his equation of highly-refined skills with automatic, everyday actions. I argue that to properly understand the phenomenology of esoteric expertise- of activities like ballet, cricket, or jazz improvisation- we need to first break them down into the 'microtasks' from which they are comprised. I argue that Montero's counter-examples to Dreyfus are focused on 'gaps in the flow,' and that Dreyfus' phenomenology of coping still holds for the moments of micro-tasks. However, I argue that Montero is right to question Dreyfus' assertion that esoteric skills are 'automatic,' and I suggest that an important phenomenological difference remains between the reflexive automaticity of an everyday skill and the intense concentration required for many forms of esoteric expertise (where 'reflexive' here means immediate, reflex-like action, as opposed to the product of reflective, deliberative thought). This difference, however, has less to do with the explicit thought that Montero supposes, but is tied rather to the quality that Heidegger (1962) called Eigentlichkeit- 'authenticity,' or, more accurately, 'owned-ness.'

I present accounts from dance and jazz improvisation, as well as sports, to argue for the phenomenological similarities between everyday and esoteric expertise, before focusing on their crucial difference. Everyday expertise is typically un-owned (uneigentlich). As I will explain in more detail below, 'un-owned' describes the way we perform everyday skills in a stereotyped way, as 'one' does them. We enact such skills automatically, with our mind 'elsewhere'- as in the typical example of driving while absorbed in conversation with our passenger. Esoteric expertise, however, to be performed at its best, requires us to 'own' the experience. Such activities are experienced as what Csikszentmihalyi (1975) calls 'flow,' which is characterised by a similar absence of thought and self-consciousness as un-owned everyday practices, but with a significant difference. Rather than being 'elsewhere,' our minds in 'owned' coping are 'lost' in the moment, which is to say, we do not perform esoteric tasks automatically while thinking of something else; in the flow, we are truly not thinking at all. I hold that owned performances are therefore better described as 'spontaneous' than as merely 'automatic.' I thereby give an account of expertise that, with Dreyfus, emphasises the absence of thought in practice, yet refines his phenomenology to argue that the un-mindedness of esoteric expertise differs in crucial ways from the mere automaticity of everyday coping.

Literature on expertise has defined two broad ways in which we might be considered experts at a subject or task, and differ in how expert knowledge is understood, with the 
distinction made along the lines of Dewey's (1922) division of knowledge into 'knowhow' and 'know-that' (pp. 177-8). Goldman (2001, p. 91), for example, distinguishes between 'skill expertise' and 'cognitive expertise,' where the former designates mostly practical skills such as violin-playing, billiards or textile design, and the latter refers more to a knowledge of facts, concepts, and propositions, as well as how to apply them. Collins and Evans (2007, p. 13) take this distinction further in their 'periodic table of expertise.' They make a fine-grained distinction between kinds of expertise in terms of the tacit and explicit knowledge that allows one to participate in the activity. They also make an important conceptual distinction between 'ubiquitous' and 'esoteric' expertise that must be incorporated into any account of expertise (ibid, pp. 15-8).

Ubiquitous or everyday expertise comprises those activities we achieve skilfully, yet which don't necessarily require the intensive training or dedication to improvement that specialised skills need. Typical examples would include untaught skills like speaking one's native language or walking up stairs, but Collins suggests it might also include skills such as balancing on a bike, or catching a ball- skills where the instruction, if any, doesn't explain to you what to actually $d o$ with your body. Collins (2010, pp. 63-4) calls this kind of teaching "coaching." For example, we might tell a child to 'keep their eye on the ball,' or encourage them to look straight ahead as they wobble on a bicycle, but the coaching doesn't in itself convey the bodily skills that are acquired as the child masters the skill.

An important difference between everyday and esoteric expertise is how we judge an expert. For many instances of esoteric expertise- ballet, for example, or musicianship-we have some pretty clear criteria about what makes an expert an expert-namely, that they can perform the tasks involved in the expertise, and perform them well. We might say an expert concert violinist can sight-read a piece by Vivaldi, but also that they hold the violin in a certain way, their fingers are positioned just so, and so on. Likewise, the success conditions for esoteric expertise are fairly clear. An expert violinist plays the piece well and without mistakes; an expert athlete wins lots of games (or at least qualifies for high-level competitions). With ubiquitous or everyday expertise, like cycling or chopping wood, however, the criteria are much less stringent, as to be an expert in this sense means only to be good enough to 'get the job done.' For although there are esoteric expert cyclists and even wood-choppers, who put great energy into perfecting their techniques, such refined techniques are not necessary to achieve everyday expertise. Thus, while your father-in-law might insist there exists one objectively most efficient way to chop wood, we can at any rate also imagine someone who has been successfully chopping wood for 20 years using a less efficient techniquealthough still efficiently enough to get the job done. They might be slightly slower, or have chronic back pain, as a result of their imperfect technique, but they are nevertheless an everyday expert; they perform the task smoothly to a standard that meets their needs. This is the sense of expertise that is central to Dreyfus' phenomenology of coping, where what makes someone an expert is less the quality of their knowledge or technique than their experience as they act. Dreyfus and Dreyfus (1986, p. 30) emphasise that the central criterion for expertise is that the practitioner does not follow explicit rules, but responds to the affordances presented by the situation (cf. Dreyfus 2005, p. 63, [n. 32]). At this stage, as I will discuss further below, the Dreyfuses do not distinguish between everyday and esoteric experts- a suburban cyclist's experience involves the same flexible responsiveness as a touriste de France, although within a less demanding context. To be an everyday expert, then, means to be able to get the job done as a matter of course- 
without attending to one's bodily movements, and perhaps with one's mind somewhere else. Whether the style or technique corresponds to that of an esoteric expert is secondary here; as far as everyday expertise is concerned, it is the practitioner's experience as they act which is important, and this is the key point I will come back to later.

There is an obvious parallel ${ }^{1}$ between everyday expertise and the everydayness (Alltäglichkeit) discussed by Heidegger (1962, p. 422; cf. p. 76) as he introduces readiness-to-hand in Being and Time. Heidegger's everydayness is described as uneigentlich, conventionally translated 'inauthentic,' but more accurately read as 'unowned.' That is to say, there is a certain lack of ownership, or a kind of automaticity, to our everyday expert actions. It is the very mark of our proficiency at such tasks that we can chop wood, hammer nails or change our car's gears with our mind on other matters. While Uneigentlichkeit and Eigentlichkeit certainly do not map perfectly onto everyday and esoteric expertise respectively, the distinction between owned and unowned actions will play an important role later in our discussion.

However, not all philosophers agree that everyday skills- precisely because of their ubiquity-ought to count as expertise. Addis (2013, p. 330), for example, finds it "odd to say" someone speaking their native language is an expert, and that it is rather the context in which a skill is used-and by implication, the explicit concepts one has absorbed-that decide whether a skill is an expertise as opposed to a general competence. In one sense, this is merely an argument over terminology. And yet there is a deeper issue at stake. Dreyfus argues for a continuum between esoteric and everyday expertise, holding that they are united by an ability to act 'in the flow,' with what he calls 'smooth coping.' What makes the actions of esoteric experts impressive, he argues, is their enactment of difficult skills in the same way that our wood-chopper approaches their everyday task. ${ }^{2}$ However, we will see in the next section that it is against just such a continuum that Montero challenges Dreyfus, arguing that he moves too quickly in extending the phenomenology of everyday expertise to that of esoteric experts.

Dreyfus' position is based largely around the claim that "thinking disrupts smooth coping," as he declares in his interpretation of the well-known case of baseballer Chuck Knoblauch's throwing errors (Dreyfus 2007, p. 354). ${ }^{3}$ Montero calls this view 'the Maxim' (2010, p. 106), or later, the 'Principle of Automaticity' (2013, p. 304). She admits it has wide anecdotal evidence, and is indeed treated as a commonplace amongst athletes and performance artists. Nevertheless, she questions the assumption that we

\footnotetext{
${ }^{1}$ And indirect line of philosophical descent, in that Collins developed many of his ideas on tacit knowledge through a reading of Polanyi (1966), who developed his through a reading of Heidegger.

${ }^{2}$ There is also a more practical use of this definition: Many skills have such a broad spectrum that any definition of 'expert' is arbitrary. Is an expert driver one who has been driving for a certain amount of time, or one who knows $x$ number of special manoeuvres, or one who can do those manoeuvres at a certain speed, and so on? By defining expertise in terms of a practitioner's awareness during the task, we find a much more consistent understanding.

${ }^{3}$ Knoblauch was a major league second baseman who became (in)famous after falling into a curious pattern of throwing errors, where he would repeatedly make mistakes with simple throws where he had ample time ahead of him, while remaining capable of accomplishing very difficult throws under time-pressure. Dreyfus concludes from this that Knoblauch's problem was that he was thinking on the simpler throws.
} 
perform at our best when we are not thinking, and argues that, even if the Maxim holds for everyday expertise, esoteric expertise actually requires a good deal of reflective cognitive effort if it is to be truly expert.

Below, I will agree with Montero on some important points that both complicate the understanding of expertise I have laid out so far, and yet also offer opportunities to clarify it. I will agree that thought- explicit, cognitive expressions- does play a role in esoteric expertise. Yet I will argue that on closer inspection, what scholars describe as esoteric expertise is actually built up out of many smaller exercises of expertise, and that esoteric expert performance is comprised of overlapping layers of coping and thought, and in an important way, the core of even esoteric expertise involves a state that, like coping, lies prior to or 'beyond' thinking.

Yet even granting such a role for thought, a final worry raised by Montero remains. Where Montero admits of un-thought actions, she shares with Dreyfus the belief that they are purely reflexive and automatic. Her criticism, therefore, is aimed at Dreyfus' extension of the 'autopilot' of everydayness into acts of esoteric expertise, arguing instead that what is impressive in such performances is precisely the opposite of stereotyped reacting. A third possibility therefore opens up, a being-in-the-flow that is experienced non-conceptually, yet is better described as truly spontaneous than reflexive or automatic. I will conclude by outlining this experience, and by briefly relating it to Heidegger's descriptions of 'authentic' and 'inauthentic' action.

Montero questions the belief that esoteric expertise accords with the 'Principle of Automaticity.' She admits that the Maxim seems to apply to everyday expertiseactivities like riding a bike or hammering a nail- where explicit attention to our bodily actions seems to draw us awry (Montero 2013, p. 305). Her criticisms are rather aimed at those who, like Dreyfus, would extend the Maxim beyond everyday actions to esoteric experts, such as ballet dancers or professional athletes, "those generally recognised as experts in their fields" (ibid). Although such a definition appears vague, Montero (2010, p. 106) believes that most experts in this sense conform to the 'ten year rule,' where the journey from novice to expert is held to take around ten years of intensive practice. ${ }^{4}$ Intensive is the key word for Montero. After we acquire everyday expertise, we tend not to engage in strenuous practice to improve upon it. Thus while almost anybody within a short time could learn to bowl a cricket ball, few of us take the time or effort to develop that skill to the level of a first class cricketer.

This intensive effort, argues Montero, means that the Maxim is not applicable to esoteric expertise (Montero 2010, pp. 115-6). And with this, her understanding of what it is to be an expert diverges from Dreyfus', who extends the everyday understanding to hold that all expert experience is characterised by the absence of explicit thought (Dreyfus 2007, p. 354). But for Montero, esoteric expertise is marked by a continuous desire to improve and she insists that this highly-motivated attitude-called kaizen in Japanese- requires explicit cognitive attention if it is to succeed (Montero 2013, p. 303). Thus, she argues, while the Maxim might be applicable to everyday expertise, it is not equally valid for esoteric. One example of this, she says, is Tiger Woods, who, as the top-ranked golfer in the world, set about quite consciously changing his swing

\footnotetext{
${ }^{4}$ Another commonly held aphorism is the '10,000 hour rule,' which holds that anyone can become expert at any skill if they put in that amount of practice. Spaced over a decade, this rule would involve intensive practice of 2-3 hours every day, suggesting the same dedication to improvement that Montero wants to emphasise.
} 
where he saw room for improvement (Montero 2010, p. 116). ${ }^{5}$ However, Woods' case also admits of a Dreyfusian reading, since during the period when he was perfecting his new swing- and, presumably, explicitly monitoring and applying concepts to his actions- his performance suffered, and even Montero admits he had a "rather dismal string of games" (ibid). But she denies that this is support for the Maxim, saying that Woods' problem was rather that he wasn't yet achieving his desired swing.

This comment is particularly revealing. Montero resists a Dreyfusian reading that would attribute Woods' "dismal" games to his conscious thinking, not just because she wants to highlight the thought involved in expert actions, but also because that would make him a 'novice' at his own swing, even though he is undoubtedly an expert in the game of golf (Montero 2010, p. 120 [n. 20]). Montero is wary of following through on this logic because there would be "very few experts left," since true experts for her, as we have just seen, are always striving to improve and hence always in a sense beginning again (ibid). Yet this point, I will now explain, raises a problem not only for Montero's definition of expertise, but also for the concept of esoteric expertise itself.

Woods' dry spell as he worked on his new swing reveals problems with Montero's definition of expertise, opening a space to question the usefulness of trying to understand expertise in this way. I suggested above that the real mark of expertise should be the expert's experience as they act. In that case, Woods- while still an expert at the broader skill-set of golf- was certainly not an expert at the 'micro-task' of his new swing. We find here a certain ambiguity in the term 'expert,' where it can be applied both to the practice of a specific technique (say, a certain golf swing), and to the overall portfolio of skills ('golf') of which the technique in question is an important, relevant, yet perhaps not strictly necessary element (Woods was a PGA champion before he developed his new swing). ${ }^{6}$ The second use of 'expert' is the most common and generally most useful, as we certainly don't want to suggest Woods is not an expert because he doesn't win every game. But as we continue, it will be important to recognise that, even within a domain, experts-as-people bear a certain 'family resemblance' to one another with regard to their particular expert micro-skills. ${ }^{7}$ Regarding examples of skill refinement like Woods' new swing, Dreyfus and Dreyfus' (1986, pp. 19-35) stages of skill acquisition apply within the expert's game. While Woods remained an expert at most aspects of golf, his learning process involved once again focusing on aspects of his technique and practising them until he had embodied themwhich was proven as he put his perfected technique into practice and started winning tournaments again.

This grates against Montero's distinction between everyday and esoteric expertise. Montero (2013, p. 305) rightly points out that driving a car is an everyday expertise for most of us because, once we've mastered it to an adequate degree, we tend not to apply any kaizen to continued improvement (this goes for most of our skills, from cooking to driving to singing- unless we really develop a passion for something, most of us, for

\footnotetext{
${ }^{5}$ Montero later, with Toner and Moran (in Toner et al. 2015: p. 1133) gives a similar account based on the more recent experience of Martin Kaymer. In the most important respects- changing stroke at the height of professional achievement, the following 'slump,' and the eventual surpassing of the original excellence- the two cases are parallel and, I hold, further support my interpretation.

${ }^{6}$ My thanks to an anonymous reviewer for suggesting the term 'portfolio' here.

${ }^{7}$ We can also imagine someone who could be an expert in the first sense without ever achieving expertise in the second-say, someone who mastered Woods' swing without ever bothering learning to putt.
} 
better or worse, content ourselves with 'good enough'). Yet the difference between an expert cook or driver and an everyday one is simply that on achieving expertise- in Dreyfus' sense of embodied coping- to an everyday level, esoteric experts use that skill as a foundation on which to build more refined skills, a process which in many ways mirrors the journey from novice to expert all over again. Toner et al. (2015) emphasise the role of mindedness in continuous improvement, citing work that shows that expert athletes must "experiment with and research" their bodies (p. 1128). Yet this attending to aspects of an existing skill presupposes its previous mastery. Expert athletes and performers need first to have developed a skill to the point where they have absorbed it in the way Dreyfus and Dreyfus describe. Only then, by bringing thought back to the skill, can they change the way they perform it- in effect, learning a new form of that skill, the process of which, as Woods' case above attests, comes with a similar crossfade of improved performance with diminishing thought.

This raises a second issue about our understanding of esoteric expertise more broadly. Most thinkers of expertise tend to speak of things like golf, cricket and ballet as tasks in and of themselves. And yet, as far as the phenomenology of expertise is concerned, these should rather be seen as emergent wholes built from micro-tasks. Cricket, for example, includes not only the different roles such as batting and bowling, but even within those roles we find a range of different skills which even the best players possess in different degrees. ${ }^{8}$ And most importantly, these micro-tasks are not performed continuously, but tend to manifest in relatively short bursts. In games such as cricket, the gaps between the truly expert micro-tasks of bowling, catching, running, and so on, are so long that to assert there is thought within the gaps is a truism. Thus, while Toner, Montero and Moran (2015, pp. 1135-7) argue that golfers think several steps ahead as they "design" a shot for a particular situation, it does not follow that such thought is present in the actual shot itself. Dreyfus would claim that to continue explicitly thinking into the micro-task of actually hitting the ball would be disruptive. Furthermore, he would claim that the kind of planning performed by the expert would be different than that of the novice- rather than applying rules, the expert would "directly see" what the situation calls for; the wind, the slope, the grain of the green would all solicit a response, rather than be calculated into a decision. ${ }^{9}$

Even in more flowing activities such as dance or basketball, there are certainly gapseven if only of a matter of instants- between actions where explicit thought could make an appearance. Our question, rather, needs to be whether there is thought in the moment of performing the expert micro-tasks. ${ }^{10}$ And it is not clear that the examples of thought within esoteric expert performance we have seen so far are anything other than thoughts arising in these gaps. Montero, for example, draws upon her own experience as a ballet dancer to detail examples of explicit thoughts she and other dancers expressed during performances. A dancer might carefully attend to a mark on the floor, or they might will

\footnotetext{
${ }^{8}$ Compare Brian Lara's cover drive to VVS Laxman's flick.

${ }^{9}$ Cf. Dreyfus $(2005$, pp. 55, 59) on the expert's direct perception of affordances.

10 'Moment' here is a technical term that refers not merey to a unit of time, but to the 'moment of the task,' that is, to the context in which a task is performed, through which elements of that task derive their significance. The moment of hitting a baseball, for example, includes waiting for the ball to be pitched, and takes the ball as something 'for hitting' and the bat as a 'for hitting with,' in contrast to the following moment of running, when the ball is something to be raced and avoided, while the bat fades into irrelevance. Cf. Heidegger (1962, pp. 118-9) on equipmental networks.
} 
commands such as "I am going to nail that coming balance" (Montero 2013, pp. 312$3)$. Yet such thoughts seem clearly to belong to the gaps in the flow. As a dancer mentally prepares for a balance, they may be performing a more routine stage-crossing in a quite automatic way, just in the way we might routinely and automatically change the gears in our car as we mentally prepare to round the difficult bend we see further ahead. Yet this does not make the execution of the balance any more 'minded' (although in the final section I will discuss a possible difference in the experienced 'flow' of the balance when compared with routine moves).

These gaps, then, can also be layered over more 'automatic' coping, revealing sideby-side cognitive processes, such as the way, as Pike (1974) holds, that a jazz soloist's active decisions presuppose a "smooth, almost automatic" use of their instrument (p. 94 [n. 6]). Similarly, Høffding (2014), after extensive interviews with a professional string quartet, finds that these expert musicians cope smoothly in performances while their minds focus on different thoughts that may or may not be relevant to their playing, with one informant describing the experience as like having "two tracks running" (p. 65; cf. p. 58). Our phenomenology thus reveals that while thought is involved in esoteric expertise, it is restricted either to gaps between moments or in gaps over moments of smooth coping. So far, this not inconsistent with the Maxim that thought interferes with truly expert action, for the micro-tasks the thinking sits over (the stage-crossing, for example) are separate from the micro-tasks the thought refers to (the balance). It would also be likely that thought could only appear over moments that are less difficult and more automatic- thus while a dancer may well think of his balance as he crosses the stage, it would be surprising to learn that he was thinking of crossing the stage during the moment of his difficult balance. ${ }^{11}$ We can therefore see that an esoteric expertise like ballet contains micro-tasks that can themselves have an everyday character or an esoteric one- characterised now by whether it is possible for the thinker to employ explicit thought over their moments of action.

I will focus more on the difference between these moments of coping in the next section. But initially, they raise a further argument that esoteric coping involves thought in a way that automatic, everyday coping does not. Montero claims that explicit, linguistic thought is an inextricable part of the very moment of performing difficult esoteric actions. She recalls whispering phrases like 'stretch-lift-whoosh' to herself during performances, in order to keep her focus right there in the moment of a sequence of movements and expressions (Montero 2013, p. 313).

Sutton (2007), however, draws a distinction between these kinds of explicit phrases and maxims, and 'thought' in the fuller, explicit sense in which it has been used so far. He calls such phrases "instructional nudges," following sociologist and jazz pianist David Sudnow who- before he had mastered the art of jazz improvisation- was often frustrated by his teacher's apparently empty 'nudges' like 'sing while you're playing,' or 'go for the jazz' (Sutton 2007, p. 773). These 'nudges' do not belong to the 'gaps,' being not "merely a preparatory tactic in the quiescent peacetime between periods of mindful activity," but become part of the action themselves (Sutton et al., p. 92). Like 'stretch-lift-whoosh,' such phrases are meaningless except as tied together with a

\footnotetext{
${ }^{11}$ That said, another version of the Maxim holds that one should think of something else while engaged in a particularly difficult bodily action, although, as I argue below, the best performances come from a state of intense concentration, albeit one that does not involve thought in the way Montero claims.
} 
practised, embodied skill. Once one has mastered the skill, however, these nudges can be used as prompts to hold oneself within the embodied moment. Sudnow (1993) calls instructional nudges "quasi-worded reflexive spark"s, which suggests that they are not fully abstractions, but nonetheless touch on explicit thought, as an instantaneous glance at verbal content that serves to orient the actor as they plunge into coping (p. 147). As Sutton puts it:

the expert's occasional use of simple maxims like 'watch the ball' or 'get the feet moving' are not instructions sent from mind to body... instead they are themselves material symbols with temporary but crucial causal roles as a 'new fulcrum for the control of action.' Thus a complex bodily pattern or set of possible movements can be compressed into and partly cued by a phrase or memory or ingrained image, bringing the player back to, rather than away from, the welllearned habits (Sutton 2007, p. 774).

And again (with his colleagues):

The function of the verbal maxim is not exhausted- perhaps no longer significantly affected- by its semantic content: rather, it operates in real time as a material symbol, an iterated and interactive self-stimulatory loop (Sutton et al. 2011, p. 92).

During practice especially, but also during performance, it is easy to see how such 'instructional nudges' could assist an expert focused on constant improvement. Toner et al. (2015) argue that 'nudges' "represent a form of mindedness because their adoption requires the performer to be consciously aware of the general feeling of their movement while executing a task" (p. 1139). Yet we must be careful to separate the nudges from the coping that is going on together with them. While 'instructional nudges' are thoughts in the moment of action, they are not embodied action themselves, for the action can be performed without the nudge. Instead, they serve to "sculpt and shape" our expert skills, rather like the 'coaching' that Collins ties to the learning of embodied skills (Sutton 2007, p. 772; cf. Collins 2010, pp. 62-3). In this respect, they are independent of embodied skill, having become an affordance calling for a response rather than explicit linguistic content. Importantly, the most effective 'nudges' do not involve an explicit tracking of the specific bodily movements they call for. Toner and colleagues themselves cite Mullen and Hardy (2010), who found that "holistic process goals" - instructional nudges or 'swing thoughts' in golf that gave vague, concentrating commands like 'easy' or 'straight'- led to better performance than "part process goals," which focused attention on particular body parts or movements (Mullen and Hardy 2010, pp. 276-7). This is consistent with what I have argued so far, that 'nudges' are not literal instructions, which is to say, they are not conceptual in Dreyfus' sense of explicit thoughts involved in actively monitoring action- monitoring which Dreyfus (2007, p. 357) would regard as lapsing out of absorbed smooth coping. Rather, as I will argue in more detail in section 4 below, 'nudges' are used to focus attention within coping, dampening out explicit thoughts that might detract from the task at hand. Hence 'holistic process goals'- which evoke a mood- are more effective than the 'partial process goals' that carve up the task into isolated elements. For this reason, it is 
probably misleading to call holistic 'nudges' propositional, as their primary purpose is not to convey propositions in the explicit way that 'partial' nudges do. ${ }^{12}$ Their real importance is to focus the actor and keep them 'in the zone.'

We can therefore identify two forms of mindedness that appear in esoteric expertise. Firstly, there is thinking 'in the gaps,' thought that is expressed between or over moments of smooth coping. And there are also 'instructional nudges' which occur during moments of practised action, used to prompt and focus embodied knowledge in real time. Thus Montero is correct to assert that esoteric expertise involves thought, but her arguments do not stand convincingly against the Maxim, as the actual moments of action within the overarching esoteric activity have a content more like that of the everyday expertise discussed earlier. That esoteric experts are more proficient within a wider repertoire of embodied actions goes without saying, and is a direct result of their kaizen. Yet what marks that proficiency is their ability to smoothly cope at difficult tasks in the same thought-free way in which the rest of us approach our own habitual tasks.

I have been suggesting that thought is restricted to the 'gaps' between and above moments of smooth coping. I have also identified 'instructional nudges' which are tied to and focus such moments. Yet in doing so, I have not fully taken into consideration another understanding of the distinction between everyday and esoteric expertise. This is that the form of awareness during our esoteric practice differs from the pure automaticity of everyday coping. Montero suggests this, but her answer finds the difference to be connected to thought, which I have argued is not pervasive in the way that she holds. In this section, I will argue that if we attend closely to the experience of coping, we can identify separate experiences which can be differentiated without invoking conceptual thought, revealing instead a phenomenological distinction in experiences of coping between the everyday and what I will call, following Csikszentmihalyi (1975, 2002), flow.

We have seen that Montero emphasises the thought within esoteric expertise. But her major blind-spot may be the example at the heart of her account- ballet. Ballet is an extremely concept-heavy example, being precisely choreographed to music that is written to be played precisely each time. Even in the midst of the performance, as Montero says, the dancer must constantly be reflecting and checking that he is on the right spot, the right distance from his partner and the other dancers. He must be aware of which way to move next, as well as keeping in mind how a certain character that he is playing ought to feel at each stage of the story. While I have no doubt ballet dancers 'lose themselves' from time to time in their performances, there are nevertheless so many fixed points in the choreography that the dancer's experience must certainly be drawn frequently into gaps of checking and reflection. Montero is thus undoubtedly justified in her assertion that even an expert ballet dancer finds himself constantly stepping into the realm of thought. However, I maintain that this is no argument against an un-minded level that the dancer enters in his moments of action. As is also the case

\footnotetext{
${ }^{12}$ As Wittgenstein (2009) pointed out, we should not let the fact that we use words to do things confuse us into inferring the presence of abstract linguistic thought (§11: pp. 9-10). On his account, the view that 'nudges' are explicit thought brings in an assumption that all language use is by its nature propositional.
} 
in ordinary human life, we slip from moments of smooth-coping into reflective thought and back again at incredibly frequent intervals- from one moment to the next.

A far better example of expert 'losing oneself in the flow' would be certain kinds of improvised modern dance and physical theatre (I'm thinking largely of butoh here, although many techniques would exemplify the point I want to make). These styles of dancing can be entirely improvised, without set choreography. ${ }^{13}$ The expert dancer in this case masters a set of techniques for moving the body, which are then used in spontaneous movement, such that the performance becomes reacting, rather than reciting. The dancer responds reflexively to her environment, to the position of her body, her partners, the props and the stage, perhaps even the audience. Similarly, while Montero says that the addition of a persona gives the ballet dancer one more element of which to remain aware, the butoh performer's training involves character work similar to method acting (Baird 2012, p. 170). The goal is to embody the character and actually feel their emotions, such that they guide and influence the movement as much as the immediate environment does.

As we see with the contrast between butoh and ballet, some activities emphasise the spontaneous more than others, with traditional western 'high' art seeming (for reasons that would be fascinating to explore but are entirely tangential to our investigation here) to particularly prefer 'concept-heavy' forms. This cultural preference may bias a lot of thinking on the subject, as we find with music, where a traditional focus on classical styles may lead thinkers to suspect that musicians must be situated in a swirl of conceptual thought even as they play. ${ }^{14}$ Here, however, one need not travel far to find a musician who can play a complex piece by rote simply through muscle-memory, with their mind entirely elsewhere. Similarly, playing along while sight-reading is not an obviously reflective process.

While these may fall under what we have been calling smooth-coping, a more interesting experience occurs when we turn to musical traditions with a large role for improvisation. Be it jazz in the West or the raga in the East, we find musicians whose expert playing is precisely not decided in advance. Like butoh, expertise in such styles requires mastering a set of techniques to be combined spontaneously. Such musicians describe the experience of playing as one of being 'in the groove,' "caught up" in a moment where ideas are "articulated as instantly as conceived (Berliner 1994, p. 388; cf. p. 349). "No lead time separates conception from expression, and the gap between intention and realization disappears" (ibid, p. 217). Pike (1974, pp. 88-9) explains that this direct experience is more akin to perceptual seeking than to structured planning, with the emphasis on 'finding' the right notes or phrases, matching Dreyfus' classic description of skilful coping, where too much explicit thought about one's action leads to mistakes or 'losing' the groove. Sudnow (1993) further emphasises the relegation of explicit thought to an 'observer' of his improvising hands, often surprising himself and thinking "look at that, that jazz just came out" (pp. 84-5).

However, the difference between 'open' styles and more rigid ones seems a difference of degree rather than of kind. Benson (2003) points out that precisely written pieces of classical music or ballet always contain Unbestimmtheitstellen, or

\footnotetext{
${ }^{13}$ Or the choreography can be quite loose. The dancer may still have to move to a mark on the stage, yet this is not done via premeditated steps. Going into the dance, and into character, the dancer lets the mark solicit them forwards- they are aware of it, of course, but not so much as an object of thought as precisely the soliciting force that Merleau-Ponty (2006, p. 168-9) describes. The movement towards it, however, remains quite open. ${ }^{14}$ Similarly, Toner et al.'s (2015) reliance on golf as a core example also betrays a preference for a particularly 'concept-heavy' activity.
} 
indeterminacies, that the performers must 'fill in,' since, aside from vague notes regarding tempo, mood and so on, the score can never relate all of the intricate variables of playing an instrument. "Not only do performers have room for improvisation," writes Benson, "but also it is required," and he thus concludes that all musical performance involves a form of improvisation (p. 82). The same point surely applies to ballet, where there is room within even the most tightly choreographed piece for a dancer to make a part their own. Indeed, as we will see in a few moments, Montero (2013, p. 314) argues that it is in how they make use of such leeway that the best dancers- the ones with 'spark'- distinguish themselves as true esoteric experts.

Where Benson (2003) argues that classical forms of music contain more improvisation than we might at first be aware of, he also holds that improvisation-heavy styles such as jazz or raga are conversely "far more organised than [they] might appear" (p. 136). It goes without saying that improvisation in such styles is no random sounding of notes, but a skill involving intense study and practice, albeit one that- certainly historically, and probably even today- tends to involve a more practical form of learning, involving playing with and imitating experts rather than learning theory (ibid, p. 140, n. 25). ${ }^{15}$ For instance, Berliner (1994, pp. 39-44) stresses the importance of jam sessions, of playing and improvising with other performers, and informal 'apprenticeship' relationships in learning to play jazz. ${ }^{16}$ While such relationships also involve the transmission of formal theory, Berliner argues that the knowledge gained directly through playing is "as essential" to jazz as technical information; playing jazz involves getting a feel from other players for what counts as good (ibid, p. 41) ${ }^{17}$ This practical form of skill-acquisition, as Gallagher (2007, p. 211) observes, has an analogy with Aristotle's phronesis or 'practical wisdom,' which can't be captured in maxims but is picked up by "hanging around with the right people." Yet as Gallagher also emphasises, just 'hanging out' - or in this case, simply listening to good improvisers- is not by itself enough; the aspiring phronimos- or musician- must actively imitate the experts.

What jazz musicians pick up, of course, are techniques which they can spontaneously put into play during performances. In this respect, they are not so different from a cricketer who, having mastered a repertoire of different strikes, demonstrates her expertise by performing the best one that each situation calls for. Pike (1974, p. 91) describes the improvised jazz solo as a trial and error process where the player takes feedback from their own playing, interspersing moments of playing with gaps of explicit, conscious judgement and 'nudges' in new directions. According to Benson (2003), even "the highly inventive improvisations" of such a celebrated player as Charlie Parker "were actually composed out of about one hundred basic musical ideas, runs, and phrases" (p. 137, [n. 17]). He continues:

\footnotetext{
${ }^{15}$ Although most jazz practitioners come to jazz having learned the fundamentals of their instruments and basic music theory (scales, chords, etc.) in more 'rigid' styles.

${ }^{16}$ Similarly, the guru-shishya ('master-apprentice') relationship is central to Indian classical music, as the basis for the student's enculturation into an understanding of music that goes beyond pure technique (Neuman 1990, pp. 50-1).

${ }^{17}$ Berliner (1994, pp. 56-7) even suggests that despite the rise of jazz as a formal subject in music conservatories, the main role of those institutions is as a locus for bringing together musicians in an era where jam sessions and touring bands have become less common.
} 
As odd as it may sound, the musician who is most prepared-not only in terms of having thought about what is to be played but even having played various possibilities- is most able to be spontaneous (Benson 2003, pp. 142-3).

This planning, however, seems akin to the 'thought in the gaps' that I have argued pervades our smooth coping at extended tasks. As such, it tells us little about the experience of playing in the flow itself. It does suggest, however, that esoteric coping has more to it than automatic everydayness. As Sutton and his colleagues (2011, p. 88) remind us, even our finely practised habitual actions like driving or playing sport require us to actively pay attention to what is going on. Even though our actions may be reflex-like and spontaneous, if we are to perform well we must remain 'in the game.'

The spontaneity of improvised music and dance is significant, because it brings us closer once again to sport. Sports are unpredictable in a way that all but the most experimental of improvised arts are not, although like performance arts they always have at least a basic structure that constrains the possibilities of the actions taking place. These structures challenge the assertion that smooth coping is automatic and instinctual, and not merely because such structures must be learned conceptually before the game can even be played. Sutton (2007, p. 775) notes a cricketing maxim similar to the Maxim, that a batter should 'play every ball on its merits.' Like the Maxim, this advice suggests 'don't think, just do' - trying to decide in advance will lead to being caught off-guard by the bowler, or to making a sloppy strike as you play the ball you were imagining, not the actual ball in front of you. Good cricket is supposed to come from simply reacting, not deliberate planning.

Yet Sutton points out that the best cricketers expressly disregard this sage advice. In the "crucial dying overs of a one-day game," for example, when the batter knows her team's only chance of winning requires her to hit several boundaries, an expert player does- indeed, must- decide in advance, and intend to turn even an unfavourable bounce into a smash hit (Sutton 2007, p. 775). In a similar way, improvising musicians might decide that a piece needs to lift or slow, or come to an end.

Such factors do not apply only to 'open' or unpredictable performances such as improvisation or sport, but also play a role in more 'precise' arts. Perhaps Montero's strongest argument against the 'Principle of Automaticity' in esoteric expertise is that "a performance on autopilot... leads to doing the same thing in the same way" (Montero 2013, p. 314). For no matter how precisely a ballet or concerto is written, there are certainly differences in how such pieces can be performed. Countless tenors have sung Puccini's 'Nessun dorma' in a technically excellent way, yet the public and critics alike judge Luciano Pavarotti's best performances as having something more. In a similar way, BB King tended to play very simple (technically speaking) guitar licks, often just a single note, yet they rarely sound flat or uninspired. Montero calls this intangible element 'spark,' and says that "performing the same piece in the same way day in and day out can result in a performance without spark"- and spark is what distinguishes the real masters from the also-rans (ibid). Thus, while it seems perfectly possible that one could be a technical expert and just 'go through the motions,' there seems to be a kind of expert performance- one that is highly prized- that is expressly not automatic in this way. This leads to the question of whether smooth coping is best described by the 'Principle of Automaticity,' even as Dreyfus does make frequent allusions to the idea of its being a kind of 'autopilot' (e.g., Dreyfus 2007, p. 358; 2009, 
p. 54). Yet what really marks esoteric smooth coping is not so much its automaticity as its spontaneity. As I will discuss below, spontaneity describes the smooth, undeliberative decisions taken during expert coping that, although they appear automatic and reflexive, are far from being stereotyped responses to certain affordances but are rather direct responses to the intricacies of the moment.

In this section, I have argued that the phenomenology of improvised performance, like sport, provides clear examples of un-minded coping, with experts responding with practised techniques to the specific situations they encounter. I have suggested that, although more rigid or 'concept-heavy' examples of expertise may tempt us to extend the role of explicit planning and deliberation into the moment of action, even set performances, at their best, are marked by a similar fluid responsiveness. However, I have denied that an absence of explicit thought here makes expert performance 'merely automatic,' but rather I have distinguished a second, spontaneous form of un-minded action. It is to this experience I will now turn.

\section{4}

I have argued against Montero by holding that esoteric expertise is not distinguished from the everyday by containing explicit thought. I argued that esoteric expertise can be broken down into moments of micro-tasks, and that the thought Montero identifies appears in the gaps between or over these moments. Nonetheless, we saw earlier that while some micro-tasks have an automaticity that lends itself to being thought over, others maintain an intensity that seems less automatic, even while it is still performed in an immediate, reflexive way. And we have just seen that really prized esoteric performances have a certain 'spark' that distinguishes them from automatic reactions. This spontaneous acting in the flow, I will argue below, is distinct from the two poles exemplified on one side by the thoughtful acting Montero describes, and on the other by the everyday coping that Dreyfus sees as its opposite. Such coping in the flow,' I aim to show, occurs when experts enter a qualitatively different mode of awareness.

We find a description of this awareness in jazz pianist Bill Evans' (1959) famous description of the recording sessions for Miles Davis' Kind of Blue, the criticallyacclaimed record that is still the biggest-selling jazz album of all time. ${ }^{18} \mathrm{He}$ begins by comparing his art to Japanese sumi-e painting:

There is a Japanese visual art in which the artist is forced to be spontaneous. He must paint on a thin stretched parchment with a special brush and black water paint in such a way that an unnatural or interrupted stroke will destroy the line or break through the parchment. Erasures or changes are impossible. These artists must practice a particular discipline, that of allowing the idea to express itself in communication with their hands in such a direct way that deliberation cannot interfere...

\footnotetext{
${ }^{18}$ With three million copies sold by 2005 , according to Bennett (ed.) (2005, p. 26).
} 
This conviction that direct deed is the most meaningful of reflections, I believe, has prompted the evolution of the extremely severe and unique disciplines of the jazz or improvising musician (Evans 1959).

What Evans says accords with what we saw Benson say earlier. The improviser's training involves not only practising a technique, but cultivating a distinct form of awareness. Being prepared is not so much planning what one will do, but preparing oneself to do it. ${ }^{19}$ Smith (1995) describes Miles Davis' style as composer and bandleader as creating a "ritual space" (p. 42). He sought to create the conditions where his musicians would be in the right state of awareness to put their techniques into practice. One way he did this was to deliberately withhold information from his musicians, so that they wouldn't try to anticipate the piece and conceptually compose responses ahead of the moment. Instead, Davis tried to instil an awareness that was bound within the moment of playing.

Miles wanted a quality of attentive musical flexibility that would lift the players to the level of co-composing interpreters; one that would encourage them to respond to the improvisational moment with the same alert freedom that he did (Smith 1995, p. 42). ${ }^{20}$

These states of focused yet open concentration seem crucial to high-level performance, and we saw earlier that instructional nudges, as holistic cues, seem to be used to induce this type of state. This form of awareness, like the state Evans describes, and that Davis seemed intent on evoking for his musicians, matches what Csikszentmihalyi (1975, pp. 36-48) calls 'flow.' Flow is based on what Maslow (1962) called 'peak experiences,' feelings of wholeness and transcendence achieved when one feels entirely absorbed in a moment or activity. Examples of flow correlate well with many of Dreyfus' examples of absorbed coping (a connection Dreyfus (2013, p. 28) acknowledges, although he does not distinguish the flow from everyday coping). A musician 'lost' in a piece, or an athlete 'in the zone' are experiencing flow, although activities as diverse as gardening or being immersed in a religious ritual could be described as flow (Csikszentmihalyi 1988, pp. 30-1). Csikszentmihalyi describes the phenomenology of flow experiences as follows:

\footnotetext{
${ }^{19}$ In Heideggerian terms, we could phrase this as: one doesn't prepare what vorhanden objects to create- this melody, for example. Rather, one prepares oneself to be able to cope with the zuhanden melodies one brings forth.

${ }^{20}$ It is almost certainly significant that the New York bebop scene from which Davis emerged was saturated with heroin. Musicians actively sought an altered state of consciousness in which to perform, and the drug offers a short-cut to a trance-like state. Interestingly, and consistently with what I have been arguing, heroinusing improvisers do not credit the drug with any positive or negative effect on musical ability. Rather, they claim it facilitates a state of concentration in which irrelevant thoughts- "internal noise," as Charlie Parker put it- dissipates, so that one is focused only on the music (see Spunt 2014, pp. 39-42). While it is beyond the scope of this paper to make too much of this connection, it is a reasonable hypothesis that the moment I am positing is has some relationship with the physical functioning of the brain, or more precisely, the inhibition of the pre-frontal cortex (which correlates with effects of heroin use; see Petry et al. 1998). The connection between drug use, the brain, and improvisation, therefore offers an interesting angle for future empirical research.
} 
1. a narrowing of the focus of consciousness on a clearly delimited stimulus field;

2. exclusion from one's awareness of irrelevant immediate stimuli, memories of past events, and contemplation of the future; hence a focusing on the unfolding present;

3. merging of action and awareness, also described as absence of doubt and critical reflection about one's current activity;

4. awareness of clear goals and unambiguous feedback, so that one knows one's standing with reference to the goals;

5. lack of concern regarding one's ability to control the situation;

6. loss of self-consciousness, which in turn may lead to a sense of transcendence of ego boundaries and of union with a larger, transpersonal system (Csikszentmihalyi 1987, p. 362).

There are certain common features between flow and everyday expertise. Most significantly is the focus on the present, which is exemplified not just in the absence of memories in a flow state, but in the different quality of memory that is retained from such a state. The absence of episodic memory ${ }^{21}$ of automatic, everyday tasks is an oftrepeated example in phenomenological literature- our arriving safely at work with little recollection of the ride over, for example, is frequently given as evidence for smooth coping. Yet Bielock and her colleagues have highlighted a similar phenomenon among experts at tasks requiring a high degree of concentration, what they call "expertiseinduced amnesia" (Bielock and Carr 2001, p. 703; Bielock et al. 2003, p. 305). In a series of studies, they found that although experts were unsurprisingly better than novices at a given task, they were worse at giving an account of the steps they took to complete it (Bielock et al. 2003, pp. 301-5). They found that

highly-skilled online performances are controlled by automated procedural knowledge that operates largely outside the scope of attention and is therefore substantially closed to explicit analysis and report (ibid, p. 305).

This was the case even when the experts were told they would be asked to detail their experiences after the fact, leading Bielock et al. (2003) to conclude that "it is as if experts cannot pay enough attention to remember as well as novices" at a practised skill (pp. 309-10). Sudnow (1993, p. 25) recalls that his jazz piano teacher had a hard time reproducing improvised phrases, often not even being aware of having created the interesting runs that caught his student's attention. "I'm not following rules so I don't really know what I just did," he would say when Sudnow asked him to stop, repeat, and explain his technique. "You have to have a feel for it" (ibid).

'Expertise-induced amnesia' supports the notion that the moments of enacted expertise are different from the gaps in which explicit thought arises. A similar phenomenon is found in the flow of intense ritual states, in which participants enter what Turner (1979) called a 'liminal' (or 'liminoid') space, which is frequently marked by a

\footnotetext{
21 'Episodic' memory (Tulving 1972, 1983) is the memory system that is experienced as a form of 'mental time travel,' allowing us to relive the details of our past experiences, and is to be distinguished from the 'semantic' memory of facts or the non-declarative memory of how to do something, which of course the expert has in abundance. Further to note 20, above, episodic memory is also associated with the pre-frontal cortex (Wheeler et al. 1997), and its absence or alteration in absorbed coping further suggests a link with the inhibition of that brain region, and an interesting lead for future research.
} 
different quality of memory after the fact. The key point here is the common poverty of episodic memory associated with both flow and everyday coping.

Another shared feature of the two states that will become significant later is a lack of self-consciousness. Once again, such a feature is taken for granted as a feature of everyday coping- Heidegger's original example of the hammer's readiness-to-hand emphasises that our dealings take place without a sense of being a subject at work (Heidegger 1962, p. 98). There is just the hammering, and the network of equipment lit up by the task. Yet flow states are also characterised by a similar lack of self-consciousness. Csikszentmihalyi gives the following informants' quotes as exemplary of the flow experience:

An expert rock climber: 'You are so involved in what you are doing [that] you aren't thinking of yourself as separate from the immediate activity... You don't see yourself as separate from what you are doing.'

A dancer...: 'Your concentration is very complete. Your mind isn't wandering, you are not thinking of something else; you are totally involved in what you are doing... Your energy is flowing very smoothly. You feel relaxed, comfortable, and energetic (Csikszentmihalyi 1975, p. 39).

[Another climber]: It's like when I was talking about things becoming 'automatic'... almost like an egoless thing in a way- somehow the right thing is done without... thinking about it or doing anything at all... It just happens... and yet you're more concentrated (ibid, p. 43). ${ }^{22}$

It is significant that the final climber distinguishes between a kind of automatic reacting and an un-thinking 'concentration' that characterises the flow, thus reinforcing flow's distinction with the smooth coping that characterises everyday dealings. For we have seen in this section that there are important parallels between both experiences, most importantly the absence of self-consciousness, and an absorption in the present that results in a different quality of memory. However, I have also argued that flow is characterised by a heightened state of concentrated awareness which distinguishes it from everyday coping, and it is to this distinction that we turn our attention in the final section.

Our phenomenology of expertise has complicated the picture of smooth coping we have seen so far. While I have argued that Montero is wrong on the pervasiveness of thought in esoteric expertise, she is right to distinguish everyday coping from expert performance. Dreyfus, on the other hand, moves too quickly in his comparison of an expert athlete 'in the zone' with everyday activities. Yet nevertheless, the parallels between everyday and flow coping are too strong to separate them completely. What, then, is the difference between automaticity and spontaneity?

\footnotetext{
${ }^{22}$ Compare Sudnow's account of his jazz improvisation: "I sing with my fingers, so to speak, and only so to speak, for there is a new 'I' that the speaking 'I' gestures toward with a pointing of the music that says: It is a singing body and this I (here, too, so to speak) sings" (Sudnow 1993, p. 152).
} 
I earlier suggested that there was a parallel between the everyday expertise we have been discussing, and the 'everydayness' (Alltäglichkeit) that Heidegger says characterises our actions. Everyday actions, for Heidegger, are uneigentlich- they are 'inauthentic' or un-owned (Heidegger 1962, p. 222). Heidegger disclaims a moral stance over inauthenticity, even where it is clear that he thinks authenticity is something we should strive for. Inauthenticity is a fact for Dasein; it is our natural state, and one to which we inevitably return (ibid, p. 220). Thus, although we should not judge 'unowned-ness' negatively, Eigentlichkeit or 'owned-ness' is nevertheless viewed as a positive overcoming of this everyday state.

Our everyday skilled actions- our hammering, driving, stair-climbing- have a sense of Uneigentlichkeit. We do not own them, but do them as 'one' does them, as das Man does. And, I submit, any action in which we have achieved a level of (everyday) expertise- that we can do automatically-we do in this un-owned way. Ratcliffe (2007, p. 73) describes this mode of acting as 'letting the world do the work.' Performance requires no special effort of concentration, because we can let go of responsibility by acting 'as we've always done,' without the need to focus ourselves on creating a unique event. Our esoteric expertise, on the other hand, when we are immersed in the flow, is eigentlich-we own it. When we are fully absorbed in an activity, 'in the zone,' the experience takes on a different character, one where we are absorbed to the exclusion of any other activity, and of thought as well.

Eigentlich flow, therefore, is a state of concentration that marks the experience of esoteric expertise. It is not the expertise itself- a practitioner still requires the skill or techne if we are to consider them truly expert; flow on its own is not enough. ${ }^{23}$ However, the experience of flow by esoteric experts belies the claim that mindedness or explicit thought is pervasive in esoteric expertise, by demonstrating how a performance can be 'mind-less' without being automatic.

Furthermore, although I have associated Eigentlichkeit with esoteric expertise and Uneigentlichkeit with the everyday, there is no sharp dividing line between which activities can be authentic and which inauthentic. Even for an esoteric expert, uneigentlich performances may be more or less frequent. A great dancer or musician can slip out of the flow and fall back on more automatic routines. Even an improviser can slip between the two modes. As Pike (1974) says of the jazz improviser:

If his search is fruitful the tonal images flow along freely without interruption. If some impeding factor arises, his inspiration may lag or lapse. At this point free productive imagery gives way to stereotyped, reproductive patterns, which are drawn from the fund of his previous jazz experience (Pike 1974, p. 90). ${ }^{24}$

In the same way, an expert martial artist fighting a novice opponent, or a lecturer giving the same talk as last year and the year before, might find themselves 'going through the motions,' falling back on habitual moves or stock phrases in an automatic way. Most activities that we can do authentically, we can do inauthentically, although it

\footnotetext{
${ }^{23}$ As a percussionist, I have had countless opportunities to witness novice drummers seemingly lost in the 'flow' with very little technē involved.

${ }^{24}$ Berliner (1994, p. 217) notes that accomplished jazz soloists always have 'crips' or stock patterns as backups for when inspiration is slow. He quotes trumpeter Tommy Turrentine: “A crip is like a crutch. It's like a brace or bridge from one idea to another. Bird [Charlie Parker] might rip off something real mean and then play a crip. And after that, he'd come out of the crip, and he'd rip off something real mean again."
} 
seems likely we need to master them authentically first- which would account for the gradually-diminishing 'buzz' we get from repeating an activity we have mastered. ${ }^{25}$ While some particularly challenging activities might perhaps only be achievable in a state of flow, the story of the jaded performer, no longer with any 'spark,' is a familiar one.

On the other hand, we need not restrict Eigentlichkeit to professional-level practices. While a rally car driver perhaps must be 'in the zone' to successfully complete a course, she might also initiate the same form of concentration when driving to the beach. Although 'one' doesn't normally garden, cook, sweep, or climb stairs in the flow, it is possible to perform everyday activities with a cultivated awareness. The practices of Taoism and Zen Buddhism, for example, with their frequent celebration of the mundane, seem designed to cultivate such an awareness, which can be brought to any activity. $^{26}$

The difference between owned and unowned actions is connected to the role of thought, although not in the way that a thinker like Montero might have suggested at the beginning of this paper. Her hypothesis was that, while everyday actions are indeed automatic, esoteric expertise is characterised by the presence of explicit thought. I have argued, however, that the explicit thought in esoteric expertise is only present in the gaps between moments, and that moments of flow are thought-free in the manner of the everyday- except that they are owned. Yet being owned, I argue, makes them even more thought-free. For what distinguishes unowned, everyday actions seems to be that we can quite easily think over the top of them. Whether it's the lecturer 'going through the motions,' the jazz musician falling back on 'crips,' or me absent-mindedly cycling home, our minds are present and thinking- only not really on the task we're immersed in. What characterises the authentic expert is that their mind is right there on the action- or, perhaps more accurately, their mind is not there at all. They have 'lost themselves' in the flow.

That is to say, automatic, unowned actions allow explicit thinking over the top because they involve a less intensive concentration than owned actions, even if, from the outside, owned actions appear just as automatic. As Csikszentmihalyi (2002) puts it:

Although the flow experience appears to be effortless, it is far from being so. It often requires strenuous physical exertion, or highly disciplined mental activity. It does not happen without the application of skilled performance. Any lapse in concentration will erase it. And yet while it lasts consciousness works smoothly, action follows action seamlessly (Csikszentmihalyi 2002, p. 54).

\footnotetext{
${ }^{25}$ Csikszentmihalyi (2002, pp. 155-7) compares the experiences of surgeons who find their work exhilarating and addictive to those for whom it has become a repetitive "drudgery." He ties a lack of challenge to dissatisfaction with even a prestigious job like surgery, suggesting that, having mastered their skill to the point where they can perform it automatically (and hence, inauthentically), they no longer get a feeling of flow from their work.

${ }^{26}$ See, e.g., Dōgen (1985a) 'Instructions for the Tenzo [cook]' (pp. 54-8, 64-5). See also Dōgen (1985b, pp. $125-8$ ), where he plays with the imagery of everyday activity, which we can read both as suggesting that the way to enlightenment is through simple activities, or that the profoundness of satori infuses even the most mundane tasks.
} 
Such flow is admittedly a fragile state, and I seriously doubt that even the best experts stay fully immersed in it for the duration of a performance or a game. Eigentlichkeit, for Heidegger, is not a permanent state that one achieves, nor even a particularly common one. Uneigentlichkeit is our default mode, and one to which we continually slip back. Even where experts have rituals, 'nudges,' or other techniques to induce the right state of concentration, it remains easily broken. Thoughts may creep in, or one might lose the groove, in which case the real experts will have stock patterns to fall back on, so to relax back into the flow. ${ }^{27}$ Yet this fact does not diminish the phenomenal reality of the flow state or its centrality to esoteric expert performance.

Dreyfus is therefore wrong to equate expert acting in the flow with everyday expertise, even though we have seen that some esoteric experts, having mastered their skills, may perform them in an automatic, unowned way, while ordinary folk may perform our everyday tasks in the owned flow. Montero is therefore correct to distinguish esoteric expertise, involving kaizen and 'spark,' from the 'Principle of Automaticity.' However, I have argued that in doing so, she has not shown that the reason for this is their use of explicit thought in the moments of action.

\section{Conclusion}

In this paper, I have defended Dreyfus' account of expertise while refining its phenomenology. I responded to Montero, who claims that esoteric expertise requires explicit thought in order to achieve its best results. I argued that everyday and esoteric expertise share an un-minded direct experience of the moment of action, and that the thought Montero identifies is restricted to 'gaps' between micro-tasks or to 'instructional nudges,' neither of which affect the essential points of Dreyfus' account. Yet I agreed with Montero that Dreyfus' extension of the 'Principle of Automaticity' from the everyday to the esoteric is problematic. Through accounts of sport and improvised performance art, I argued that un-minded moments of esoteric expertise, unlike those of everyday expertise, tend to be experienced as flow. Drawing on Heidegger's account of Eigentlichkeit, I argued that 'owned,' flow experiences are characterised by an absorption in which explicit thought disappears, whereas everyday moments have an automaticity that allows them to recede into the background, such that explicit thought on different matters can arise without detriment to the performance. However, I also noted that these relationships have a degree of contingency- esoteric expertise can be performed in an 'un-owned' way, while everyday tasks can also be 'owned.' Yet typically, our everydayness, as Heidegger observed, is uneigentlich, while our very best esoteric performances, as Montero holds, require a spontaneity that is more than reflexive automaticity.

Acknowledgments My thanks to Simon James and Ben Smith for discussing and commenting on this paper at length, and to Salomé Jacob and two anonymous referees for their comments and suggestions for improvement. Thanks also to an audience of the Durham University Eidos society, and to Matthew Ratcliffe, for their helpful comments on a earlier version of this paper.

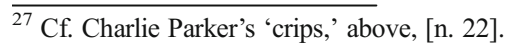


Open Access This article is distributed under the terms of the Creative Commons Attribution 4.0 International License (http://creativecommons.org/licenses/by/4.0/), which permits unrestricted use, distribution, and reproduction in any medium, provided you give appropriate credit to the original author(s) and the source, provide a link to the Creative Commons license, and indicate if changes were made.

\section{References}

Addis, M. (2013). Linguistic competence and expertise. Phenomenology and the Cognitive Sciences, 12, 327336.

Baird, B. (2012). Hijikata Tatsumi and Butoh: Dancing in a pool of gray gifts. New York: Palgrave Macmillan.

Bennett, J. (Ed.). (2005). The top 100 best-selling albums. London: Amber Books.

Benson, B. E. (2003). The improvisation of musical dialogue. Cambridge: Cambridge University Press.

Berliner, P. F. (1994). Thinking in Jazz: The infinite art of improvisation. Chicago: University of Chicago Press.

Bielock, S. L., \& Carr, T. H. (2001). On the fragility of skilled performance: What governs chocking under pressure? Journal of Experimental Psychology: General, 130, 701-725.

Bielock, S. L., Wierenga, S. A., \& Carr, T. H. (2003). Memory and expertise: What do experienced athletes remember? In J. L. Starkes \& K. A. Ericsson (Eds.), Expert performance in sports (Vol. 12, pp. 295-320). Champaign: Human Kinetics.

Collins, H. M. (2010). Tacit and explicit knowledge. Chicago: University of Chicago Press.

Collins, H. M., \& Evans, R. (2007). Rethinking expertise. Chicago: University of Chicago Press.

Csikszentmihalyi, M. (1975). Beyond boredom and anxiety. San Francisco: Jossey-Bass Publishers.

Csikszentmihalyi, M. (1987). Flow Experience. In M. Eliade (Ed.), The encyclopedia of religion (Vol. 5, pp. 361-363). New York: Macmillan.

Csikszentmihalyi, M. (1988). The flow experience and its significance for human psychology. In M. Csikszentmihalyi \& I. S. Csikszentmihalyi (Eds.), Optimal experience: Psychological studies of flow in consciousness (Vol. 2, pp. 15-35). Cambridge: Cambridge University Press.

Csikszentmihalyi, M. (2002). Flow: The classic work on how to achieve happiness. London: Rider.

Dewey, J. (1922). Human nature and conduct: An introduction to social psychology. London: George Allen \& Unwin.

Dōgen. (1985a). Instructions for the Tenzo. In K. Tanahashi (Ed.), Moon in a dewdrop: Writings of Zen master Dōgen (pp. 53-66). San Francisco: North Point Press.

Dōgen. (1985b). Everyday activity. In K. Tanahashi (Ed.), Moon in a dewdrop: Writings of Zen master Dōgen (pp. 124-128). San Francisco: North Point Press.

Dreyfus, H. L. (2005). Overcoming the myth of the mental: how philosophers can profit from the phenomenology of everyday expertise. Proceedings and Addresses of the American Philosophical Association, $79(2), 47-65$.

Dreyfus, H. L. (2007). The return of the myth of the mental. Inquiry, 50(4), 352-365.

Dreyfus, H. L. (2009). How representational cognitivism failed and is being replaced by body/world coupling. In K. Leidlmair (Ed.), After cognitivism (pp. 39-73). Dordrecht: Springer.

Dreyfus, H. L. (2013). The myth of the pervasiveness of the mental. In J. K. Schear (Ed.), Mind, reason, and being-in-the-world: The Mcdowell-Dreyfus debate (Vol. 1, pp. 15-40). Abingdon: Routledge.

Dreyfus, H. L., \& Dreyfus, S. E. (1986). Mind over machine. Oxford: Blackwell.

Evans, B. (1959). "Improvisation in Jazz", liner notes to miles Davis, kind of blue [audio recording]. New York: Columbia.

Goldman, A. I. (2001). Experts: which one should you trust? Philosophy and Phenomenological Research, 63(1), 85-110.

Heidegger, M. (1962). In J. Macquarrie \& E. Robinson (Eds.), Being and time. London: SCM Press.

Høffding, S. (2014). What is skilled coping? Journal of Consciousness Studies, 21(9-10), 49-73.

Maslow, A. H. (1962). Lessons from the peak experiences. Journal of Humanistic Psychology, 2(1), 9-18.

Merleau-Ponty, M. (2006). The structure of behaviour. Pittsburgh: Duquesne University Press.

Montero, B. G. (2010). Does bodily awareness interfere with highly skilled movement? Inquiry, 53(2), 105122 .

Montero, B. G. (2013). A dancer reflects. In J. K. Schear (Ed.), Mind, reason, and being-in-the-world: The Mcdowell-Dreyfus debate (Vol. 14, pp. 303-319). Abingdon: Routledge. 
Mullen, R., \& Hardy, L. (2010). Conscious processing and the process goal paradox. Journal of Sport and Exercise Psychology, 32, 275-297.

Neuman, D. M. (1990). The life of music in North India: The organization of an artistic tradition. Chicago: University of Chicago Press.

Petry, N. M., Bickel, W. K., \& Arnett, M. (1998). Shortened time horizons and insensitivity to future consequences in heroin addicts. Addiction, 93(5), 729-738.

Pike, A. (1974). A phenomenology of jazz. Journal of Jazz Studies, 2(1), 88-94.

Polanyi, M. (1966). The logic of tacit interference. Philosophy, 41(1), 1-18.

Ratcliffe, M. (2007). Rethinking commonsense psychology: A critique of folk psychology, theory of mind and simulation. Basingstoke: Palgrave Macmillan.

Smith, C. (1995). A sense of the possible: Miles Davis and the semiotics of improvised performance. TDR, 39(3), 41-55.

Spunt, B. (2014). Heroin and music in New York City. New York: Palgrave Macmillan.

Sudnow, D. (1993). Ways of the hand: The organization of improvised conduct. Cambrdige: MIT Press.

Sutton, J. (2007). Batting, habit and memory: The embodied mind and the nature of skill. Sport in Society: Cultures, Commerce, Media Politics, 10(5), 763-786.

Sutton, J., McIlwain, D., Christensen, W., \& Geeves, A. (2011). Applying intelligence to the reflexes: embodied skills and habits between Dreyfus and Descartes. Journal of the British Society for Phenomenology, 42(1), 78-103.

Toner, J., Montero, B. G., \& Moran, A. (2015). Considering the role of cognitive control in expert performance. Phenomenology and the Cognitive Sciences, 14, 1127-1144.

Tulving, E. (1972). Episodic and semantic memory. In E. Tulving \& W. Donaldson (Eds.), Organization of memory (pp. 381-403). New York: Academia Press.

Tulving, E. (1983). Elements of episodic memory. Oxford: Oxford University Press.

Turner, V. W. (1979). Frame, flow and reflection: ritual and drama as public liminality. Japanese Journal of Religious Studies, 6(4), 465-499.

Wheeler, M. A., Stuss, D. T., \& Tulving, E. (1997). Toward a theory of episodic memory: the frontal lobes and autonoetic consciousness. Psychological Bulletin, 121(3), 331-354.

Wittgenstein, L. (2009). Philosophiche Untersuchungen/Philosophical Investigations, 4th Edition, trans. G. E. M Anscombe, P. M. S. Hacker \& J. Schulte, Chichester: Wiley-Blackwell. 